\title{
ARQUITETURA DO PROCESSAMENTO COGNITIVO: EFEITO RACIONAL E EFEITO EMOCIONAL
}

\author{
Cognitive Processing Architecture: \\ Rational Effect and Emotional Effect efecto racional y efecto emocional \\ Sebastião Lourenço dos Santos \\ Universidade Estadual de Ponta Grossa (UEPG), \\ Departamento de Estudos da Linguagem, Ponta Grossa, PR, Brasil \\ Elena Godoy \\ Universidade Federal do Paraná (UFPR), \\ Programa de Pós-graduação de Letras, Curitiba, PR, Brasil
}

\begin{abstract}
Resumo: O estudo do efeito da razão e das emoções na interpretação humana em uma perspectiva pragmática se justifica pelo fato de que no âmbito das ciências cognitivas as investigações que envolvem o uso da linguagem associada às emoções ainda são tímidas. Tomando como referência a teoria da relevância (SPERBER; WILSON, 2001), as neurociências cognitivas (GAZZANIGA; IVRY; MAGNUM, 2006; DAMÁSIO, 1994, 2004) e a psicologia cognitiva (LEDOUX, 1996; STERNBERG, 2010), o objetivo deste estudo é advogar em favor de uma arquitetura mental que congrega razão e emoções. A partir da modelação da interpretação de um enunciado noticiando a frustração de uma expectativa, argumenta-se que, em um ato comunicativo, o desejo - ao fazer uma ponte entre a razão, que opera a partir da valoração das representações contextuais, e as emoções, que atribuem níveis afetivos às representações mentais - é o gatilho para a atribuição de relevância.
\end{abstract}

Palavras-chave: Emoção. Razão. Relevância. Interpretação.

\begin{abstract}
The study regarding the effect of reason and emotions effect on human interpretation, through a pragmatic perspective, justifies itself over the fact, in the cognitive sciences, the investigations involving language use associated to emotions are still quite incipient. Taking as reference the Relevance Theory (SPERBER; WILSON, 2001), the cognitive neurosciences (GAZZANIGA; IVRY; MAGNUM, 2006 and DAMÁSIO, 1994, 2004) and the cognitive psychology (LEDOUX, 1996 and STERNBERG, 2010), the objective of this study is to advocate in favor of a mental architecture that forgathers reason and emotions in the interpretation. Based on the modeling of the interpretation of an utterance that reports the frustration of an expectation, we argue that, in a communicative act, the desire is a trigger for the attribution of relevance when serving as a link between reason, which operates from the valuation of contextual representations, and emotions, which attribute affective levels to mental representations.
\end{abstract}

Keywords: Emotion. Reason. Relevance. Interpretation.

\footnotetext{
* Docente da Universidade Estadual de Ponta Grossa. ORCID: https://orcid.org/0000-0001-5340-3362. Email: lorecutp@hotmail.com.

** Docente da Universidade Federal do Paraná. ORCID: https:// http://orcid.org/0000-0003-1881-6932. Email: elena.godoi@gmail.com.
} 
Resumen: El estudio del efecto de la razón y de las emociones en la interpretación humana por intermedio de la pragmática se justifica porque, en el ámbito de las ciencias cognitivas, las investigaciones que involucran el uso del lenguaje consignada a las emociones son aún bastante tímidas. Tomándose como referencia la Teoría de la Pertinencia (SPERBER; WILSON, 2001), las neurociencias cognitivas (GAZZANIGA; IVRY; MAGNUM, 2006 y DAMÁSIO, 1994, 2004) y la psicología cognitiva (LEDOUX, 1996 y STERNBERG, 2010), el objetivo de este estudio es abogar en favor de una arquitectura mental que congrega razón y emociones en la interpretación. Partiendo del modelado de la interpretación de un enunciado que reporta la frustración de una expectativa, argumentamos que, en un acto comunicativo, el deseo - al hacer un puente entre la razón, que opera desde la valoración de las representaciones contextuales, y las emociones, que atribuyen niveles afectivos a las representaciones mentales - es el detonante para la atribución de relevancia.

Palabras-clave: Emoción. Razón. Pertinencia. Interpretación.

\section{INTRODUÇÃO}

O atleta paraolímpico brasileiro Thiago Paulino, recordista mundial do arremesso de peso classe F57 (cadeirantes com sequelas de poliomielite, lesões medulares ou amputações), conquistou a medalha de ouro nos Jogos Paraolímpicos de Tóquio, no dia 3 de setembro de 2021. Dos seis arremessos que os atletas podem executar, o primeiro lançamento de Thiago atingiu 14,77 metros, o segundo cravou 15 metros e o terceiro chegou a 15,10 metros. Thiago queimou o quarto e quinto arremessos e abriu mão do sexto arremesso, decisão que lhe custou caro. Seus dois oponentes, o brasileiro Marco Aurélio Borges e o chinês Guoshan Wu, atingiram a marca de 14,85 metros e 15 metros, respectivamente.

Os atletas da classe F57 competem sentados e devem manter os glúteos em uma espécie de plataforma plana. O Comitê Olímpico Chinês protestou durante a competição, alegando que o atleta brasileiro havia levantado os glúteos ao executar os dois arremessos que ultrapassaram os 15 metros. Os juízes da prova, contudo, analisaram os vídeos e concluíram que Thiago havia feito os arremessos corretamente. Thiago saiu o Estádio Nacional de Tóquio campeão da modalidade F57.

Na manhã de sábado, porém, quando estava a caminho do pódio para a premiação, Thiago foi avisado pelo Comitê Brasileiro que os chineses haviam apelado ao Comitê Paralímpico Internacional, que, sem maiores explicações, anulou seus dois melhores arremessos. Resultado: o chinês levou a medalha de ouro, Marco Aurélio Borges ficou com a medalha de prata e Thiago com a medalha de bronze.

Magoado e extremamente indignado, Thiago lamentou: "Eu estava indo para a premiação, achando que eu ia ouvir o hino, mais uma vez, eu ia pegar a minha medalha de ouro, e acabei descobrindo que eu era bronze". No pódio, Thiago protestou fazendo sinal de negativo com a mão. "Eu me senti prejudicado, injustiçado, foi o modo que eu demonstrei que não aceitaria aquela medalha, porque eu sabia que eu tinha sido medalha de ouro e essa medalha foi retirada de mim de uma forma muito cruel", disse Thiago.

Ao projetarmos um recorte temporal para o instante em que Thiago foi informado pela comissão brasileira da perda da medalha de ouro, nos deparamos com algumas questões cognitivo-inferenciais sobre o processamento mental do atleta. Devem ser analisadas à luz pragmática cognitiva questões como (a) o que disse a pessoa do comitê 
brasileiro a Thiago sobre a perda da medalha de ouro; (b) quais estruturas cognitivas do atleta foram ativadas pelo enunciado desse falante; (c) que tipo de efeitos esse suposto enunciado provocou; (d) que estruturas foram acionadas, racionais, emocionais ou ambas. É sobre essas e outras questões que trataremos no presente artigo.

O interesse pela influência das emoções na linguagem humana remonta a Grécia antiga. Ao longo da história, no entanto, a dicotomia corpo/mente mostrou-se bastante aguda, principalmente na Filosofia com Espinosa, Santo Agostinho, Kant e Descartes, para quem as emoções seriam sinal de distúrbio e uma mente sadia seria aquela que estivesse livre das paixões. Esse modelo dicotômico de pensamento, alcunhado de "razão nobre" por Damásio (1994), fez com que filósofos, durante séculos, e linguistas, posteriormente, praticamente banissem as emoções dos estudos da linguagem ${ }^{1}$.

A teoria da relevância, modelo proposto por Sperber e Wilson (2001) para a comunicação humana, segue a tradição racionalista da razão nobre e postula que a cognição é orientada para os estímulos que são potencialmente mais relevantes na interação conversacional, processando-os de maneira mais produtiva, ou seja, minimizando esforços (custos) e maximizando efeitos (benefícios). Essa relação entre esforço e efeito é chave para o conceito de relevância: quanto maior o benefício cognitivo e menor o custo de processamento de um enunciado, maior é sua relevância. Os autores presumem que um input informativo é otimamente relevante se e somente se atender a duas cláusulas procedurais: a) ser relevante o suficiente para merecer o esforço de processamento do ouvinte; b) ser o mais relevante compatível com as habilidades e preferências do falante.

O modelo cognitivo-racionalista de Sperber e Wilson (2001) se aplica sem restrições à descrição do processamento cognitivo de informações, mas não dá conta dos casos em que certos enunciados parecem ter maiores benefícios emocionais que informativos. É o caso, por exemplo, do clichê afetivo "Eu te amo" repetido inúmeras vezes entre namorados e casais. Costa (2005) classifica este exemplo como "irrelevâncias da relevância", uma vez que a informação é a mesma nas suas diversas ocorrências, isto é, não há benefícios informativos nessas interações ${ }^{2}$.

Segundo Carston e Wilson (2019), estudos de enunciados como o analisado por Costa são negligenciados pelos estudos pragmáticos, uma vez que privilegiam, na maioria das vezes, casos de indeterminância, indiretividade, ironia ou vagueza. O estudo de Carston e Wilson segue a direção do que Moeschler (2009) e Blakemore (2011) chamam conteúdos descritivamente inefáveis ou, mais especificamente, efeitos não proposicionais - conteúdos que não podem ser nem inferidos como significados ou proposições representacionais, nem parafraseados. Sperber e Wilson (2001) classificam esses efeitos não proposicionais como implicaturas fracamente comunicadas.

A partir da perspectiva cognitivista de que o processamento da linguagem verbal aciona em conjunto razão e emoção, nosso objetivo neste estudo é advogar em favor de

\footnotetext{
${ }^{1}$ Podemos mencionar os estudos de William James (1884), Carl Lange (1922), Walter Cannon (1927), Phillip Bard (1928), Jamez Papez (1937), Stanley Schachter e Jerome Singer (1962), entre outros.

${ }^{2}$ Costa (2005) problematiza sete casos de incompatibilidade da relevância. Rauen (2008) produz hipóteses alternativas para todos esses casos.
} 
uma arquitetura da interpretação humana que permite descrever como a relevância opera no processamento de efeitos informativos e emotivos. A descrição proposta segue os preceitos da teoria da relevância (SPERBER; WILSON, 2001), das neurociências cognitivas (GAZZANIGA; IVRY; MAGNUM, 2006; DAMÁSIO, 1994, 2004) e da psicologia cognitiva (LEDOUX, 1996; STERNBERG, 2010).

Do ponto de vista textual, estruturamos o estudo em três segmentos dedicados (a) a uma revisão teórica sobre o tratamento das emoções na perspectiva da pragmática cognitiva, (b) a uma reflexão sobre a interação entre emoções e sentimentos na interpretação humana, e (c) a uma descrição de como a relevância opera sobre os efeitos racional e emocional. Para dar conta dessa demanda, analisamos o processamento de um enunciado hipotético sobre a informação da perda da medalha de ouro ao atleta paraolímpico Thiago Paulino.

\section{TEORIZANDO AS EMOÇÕES}

Os recentes estudos pragmáticos, pareados com descobertas das neurociências cognitivas e da psicologia cognitiva, possibilitaram vários insights novos aos estudos da linguagem e inspiraram inúmeros ensaios sobre o efeito das emoções na interpretação de enunciados. A crescente literatura pragmática sobre o significado afetivo e sobre os chamados efeitos não proposicionais sugere que a interpretação se ancora em duas instâncias mentais responsáveis por efeitos informativos e emotivos.

A presunção dessas instâncias de processamento interpretativo flerta com a abordagem de Cosmides e Tooby (2008) de que a mente humana evoluiu em resposta a problemas adaptativos enfrentados por nossos ancestrais e gerou uma arquitetura neural própria da espécie (MERCIER; SPERBER, 2017). Tais considerações, alinhadas aos princípios da teoria da relevância, nos encorajaram a propor um quadro sinótico dos efeitos informativo e emotivo no processamento de enunciados. A partir desse quadro sinótico de arquitetura de efeitos, tentaremos demonstrar os seguintes passos do processo interpretativo: (a) a seleção de um input linguístico para o sistema cognitivo, (b) o início do processo interpretativo, (c) o gatilho de relevância para o enunciado, (d) a origem dos efeitos informativo e emotivo, (e) o que eles são, (f) quais estruturas mentais são responsáveis por eles e $(\mathrm{g})$ como tais estruturas se conectam mentalmente.

Atualmente não há na literatura pragmática uma abordagem teórica das emoções que dê conta da descrição linguística, cognitiva e orgânico-funcional do processo de interpretação de enunciados. Os poucos estudos que se dispõem a teorizar as emoções numa perspectiva pragmática ficam aquém daquilo que se propõem. O estudo de Schnall (2005), por exemplo, não pode ser considerado uma teoria pragmática das emoções, pois suscita apenas que as experiências emocionais podem ser descritas por diferentes palavras, e é o contexto social quem define o uso de uma ou outra forma expressiva. $\mathrm{O}$ estudo de Scarantino (2017), por sua vez, adapta a teoria dos atos de fala, especialmente a taxionomia de Searle (1969/1981), para explicar os atos emocionais pragmaticamente. No entanto, a proposta mostra-se incompleta por não apresentar os requisitos teóricos que a descrição da comunicação humana e seus efeitos exige, requisitos esses que ultrapassam o escopo dos atos de fala. 
Na tentativa de trazer as emoções para o centro das discussões pragmáticas, estudo do linguista Tim Wharton, juntamente com o pesquisador do Centro Suíço de Ciências Afetivas $^{3}$ David Sander, em parceria com os cientistas afetivos Daniel Dukes e Steve Oswald e o filósofo Constant Bonard, traça o objetivo arrojado de "corrigir" o que eles percebem ser um "desequilíbrio nas teorias de interpretação de enunciados"4 (WHARTON et al, 2021, p. 259).

A proposta de Wharton et al (2021) reúne o conceito de relevância desenvolvido pela teoria da relevância com o conceito de relevância desenvolvido pelas ciências afetivas. Eles ressaltam que o conceito de relevância em teoria da relevância é um construto derivado do balanço ótimo de efeitos e esforços cognitivos, enquanto o conceito de relevância "nas ciências afetivas é a relevância de um estímulo particular para os objetivos da pessoa em quem a emoção está sendo eliciada, os estímulos sendo obstrutivos ou conducentes a esses objetivos" 5 (p. 265). Para os pesquisadores, objetivo é "um termo guarda-chuva que abrange preocupações, anseios, planos, ideais, o que é desejado, necessário ou é o objeto de qualquer outro estado mental motivador”6 (p. 265). Assim, eles argumentam que as ciências afetivas, ao defenderem a ideia de que um objeto/situação é relevante se aumentar a probabilidade de satisfação ou insatisfação do indivíduo, e a pragmática orientada pela relevância, ao defender que o processamento se pauta numa relação custo/benefício cognitivo informativo, "podem, muito bem, estar envolvidas no estudo dos mesmos fenômenos, mas simplesmente de perspectivas diferentes" $"$ (p. 265).

Destarte, visto que as neurociências cognitivas e a psicologia cognitiva fornecem um arcabouço científico sobre como as emoções influenciam a comunicação humana, para demonstrar que o efeito informativo está numa relação de contraparte emotiva de significação, norteamos nosso estudo partindo da hipótese de que, em um ato comunicativo, o desejo - ao fazer uma ponte entre a razão, que opera a partir da valoração das representações contextuais, e as emoções, que atribuem níveis afetivos às representações mentais - é o gatilho da relevância do enunciado.

Cosmides e Tooby (2008) descrevem as emoções como um programa cognitivo superordenado, cuja função é regular ou mobilizar subprogramas cognitivos responsáveis pela percepção, atenção, escolha de metas, coleta de informações, mudanças fisiológicas e especialização em certos tipos de inferências. Essa visão programática entre camadas sensíveis à recepção e a representação inferencial, nos permite afirmar que, de acordo com Gazzaniga, Ivry e Magnum (2006), emoções e cognição racional, embora executem atividades independentes, são interdependentes.

${ }^{3}$ O Centro Suíço de Ciências Afetivas de Genebra, fundado em 2003, é dirigido pelo professor David Sander e possui projetos focados em avaliação cognitiva, expressão, regulação social e jurídica, normas e valores e emoções estéticas. O Centro pesquisa emoções nas áreas da neurociência cognitiva, psicologia, linguística, filosofia, economia, arqueologia e computação afetiva.

${ }^{4}$ No original: "imbalance in theories of utterance interpretation".

${ }^{5}$ No original: "in the affective sciences is the relevance of a particular stimulus to the goals of the person in whom the emotion is being elicited, the stimuli being either obstructive or conducive to these goals".

${ }^{6}$ No original: "an umbrella term encompassing concerns, urges, plans, ideals, what is desired, needed, or is the object of any other motivating mental state".

7 No original: "may well be involved in studying the same phenomena, but simply from different perspectives". 
A partir da perspectiva naturalista-evolutiva de que a emoção é uma reação mental adaptativa a uma mudança situacional (COSMIDES; TOOBY, 2008), constituindo inicialmente o sistema de defesa do indivíduo (LEDOUX, 1996), convencionamos neste estudo que os sentimentos, enquanto experiências das emoções, constituem estados afetivos que formam a 'memória emotiva' do indivíduo. Sendo assim, vale perguntar que estados emocionais foram ativados no instante em que Thiago Paulino recebeu a informação da perda da medalha.

Damásio (1994) defende a ideia de que em processos de tomada de decisão os milênios de evolução formataram a mente humana para, mesmo inconscientemente (DI BIASE et al, 2005; HILL, 2011), "desejar" sempre o bem-estar. De acordo com Araújo (2018), na psicologia/psicanálise, o desejo é um impulso complexo que nasce das experiências de satisfação, que são memorizadas como imagens das percepções e representações sensoriais. Segundo a autora, o desejo é o movimento psíquico-cognitivo emergente da necessidade da retomada da imagem mnêmica, isto é, da necessidade do reestabelecimento da primeira satisfação vivenciada. Um exemplo entre humanos é o registro mnêmico da primeira vez que o bebê mama, criando, assim, a relação desejo/necessidade e vice-versa. Carter et al (2012), por sua vez, ressaltam que o desejo se constitui por dois componentes distintos: querer e gostar. Enquanto gostar se liga à obtenção de prazer, querer está associado à busca real pelas coisas da vida ${ }^{8}$.

O filósofo holandês Baruch de Espinosa descreve o desejo como um esforço inato que nutre o homem de uma força interna que tende a opor-se a tudo que ameaça sua existência. Afinal, escreve o filósofo, "[...] o desejo (Cupiditas) é a própria essência humana, enquanto esta é concebida como determinada a fazer algo por uma afecção qualquer nela verificada" (ESPINOSA, 1997, p. 323). Espinosa chama de conatus o esforço de preservação humana. Na proposição XXVI, da Ética, o filósofo escreve: “Tudo aquilo por que nos esforçamos pela Razão não é outra coisa que conhecer; e a alma, na medida em que usa da Razão, não julga que nenhuma outra coisa lhe seja útil, senão aquela que conduz ao conhecimento" (1997, p. 360). De acordo com Silva (2011), o conatus é o desejo que impulsiona a cognição humana ao aperfeiçoamento epistêmico.

Partindo da premissa de que o desejo é a força que orienta tudo aquilo que queremos usufruir ou possuir (CHAUÍ, 2011), as ponderações de Espinosa (1997) e de Carter et al (2012) sugerem que a interpretação humana imbrica dois níveis de desejos: o desejo racional, com vistas ao conhecimento, e o desejo emocional, com vistas ao bem-estar. Nos próximos parágrafos, teceremos argumentos em favor de uma arquitetura do processamento que permite explicar como o desejo dispara a relevância para os efeitos informativo e emocional na interpretação de enunciados.

\section{ARQUITETURA DO EFEITO}

Estudos recentes apontam novas direções de pesquisa no domínio do significado e dos efeitos emotivos e, em consequência, surgem novas propostas sobre as possibilidades de tratá-los (MOESCHLER, 2009; BLAKEMORE, 2011; SPERBER; WILSON, 2015; WHARTON; STREY, 2017; WILSON; CARSTON, 2019; SAUSSURE; WHARTON,

\footnotetext{
${ }^{8}$ Essa perspectiva sugere que o desejo perfaz uma interface ente o componente psíquico e o somático.
} 
2020; WHARTON et al, 2021, entre outros). Tais estudos apontam para os chamados conteúdos inefáveis ou não proposicionais, ou seja, que não envolvem relevância informativa, no sentido de derivação de efeitos cognitivos, mas relevância emocional.

Com a finalidade de descrever o processamento dos efeitos informativo e emotivo, esquematizamos na figura 1, a seguir, o que hipotetizamos ser a arquitetura do processamento cognitivo na interpretação de enunciados. Embora o esquema possibilite uma visualização ampla dos processos de interpretação, esta proposta não esgota a discussão sobre a natureza da relevância e dos efeitos cognitivos na interpretação.

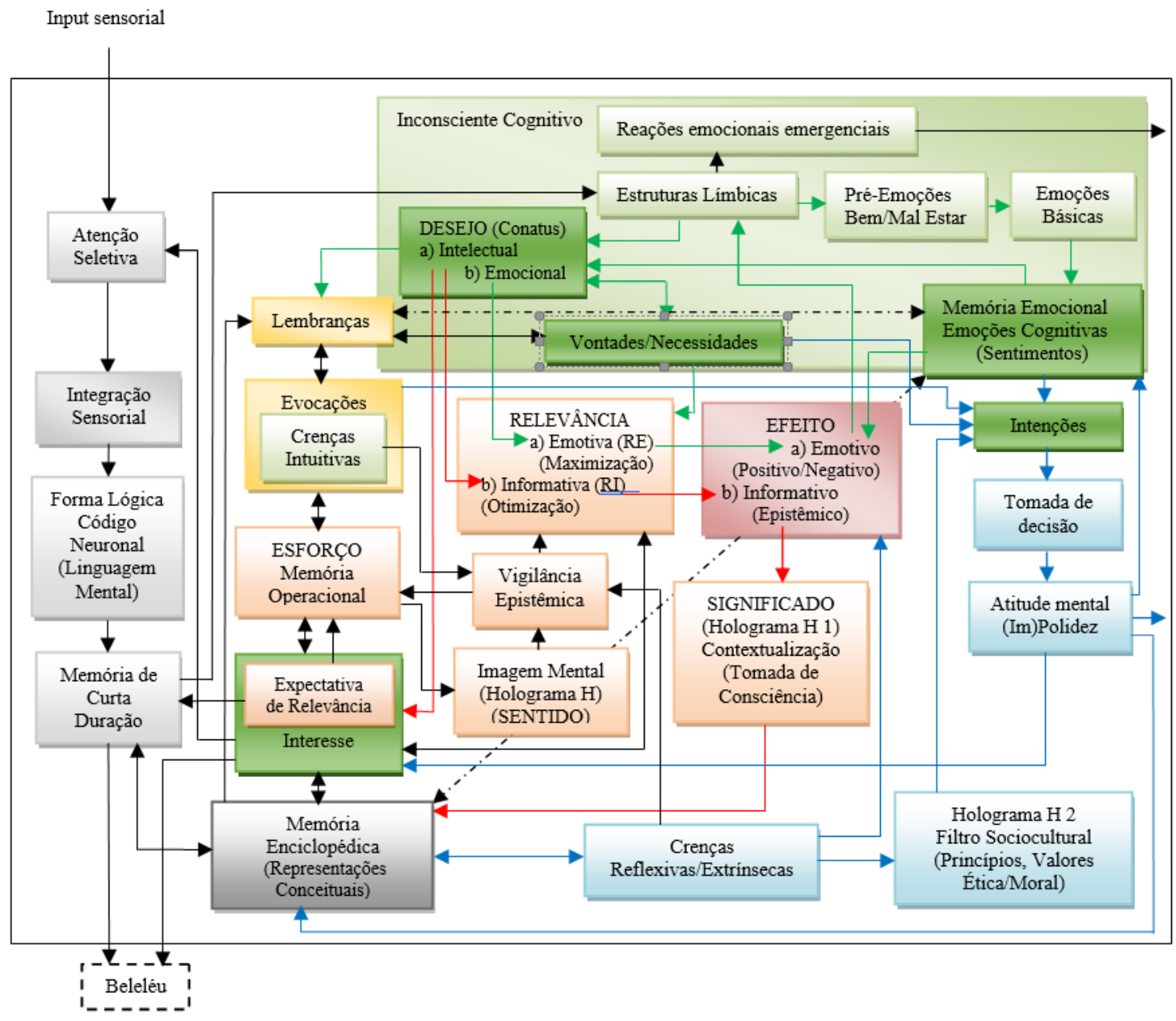

Figura 1 - Arquitetura do processamento do efeito informativo e emotivo

Fonte: Autores.

Antes de entrarmos na descrição da figura 1, chamamos a atenção para algumas convenções adotadas no esquema:

a) a disposição em blocos é mera exposição didática, posto que, organicamente, a cognição humana imbrica uma complexa rede de conexões do sistema nervoso central;

b) algumas conexões se ligam à borda dos blocos enquanto outras se conectam internamente a eles, de tal modo que, no primeiro caso, a conexão é processual (geral) e, no segundo, a conexão é sistêmica (restrita); 
c) a conexão pontilhada bidirecional entre a 'memória enciclopédica' e a 'memória emotiva' e a que une a 'memória afetiva' à estrutura 'lembranças' representa operacionalidade mútua (simbiose) entre estruturas (a mesma convenção operacional vale para as setas bidirecionais contínuas de outras estruturas), de tal modo que, no primeiro caso, dizemos que a conexão é em processo, porque opera sobre o curso da interpretação e, no segundo caso, dizemos que a conexão é sistêmica, porque as estruturas são ativadas apenas quando uma excita a outra;

d) 'beleléu' é, alegoricamente, a instância mental para onde, presumivelmente, a cognição envia as formas lógicas dos inputs não selecionados no processamento - as informações descartadas para o 'beleléu' são excluídas do raciocínio dedutivo, isto é, não podem ser novamente trazidas para o processamento.

e) as estruturas 'lembranças' e 'evocações' são, em princípio, atividades internas à mente, ou seja, independem dos inputs de entrada. Enquanto as 'lembranças' trazem as imagens mentais das experiências epistêmicas e emotivas para o pensamento, as 'evocações' constituem os próprios pensamentos do indivíduo, isto é, são atividades mentais que promovem planejamentos, projeções e ações sobre o presente e o futuro. É o caso, dentre tantos, dos pensamentos que se formam quando o indivíduo está dirigindo sozinho em uma autoestrada, almoçando em um restaurante ou perseguindo o sono na cama.

Nos itens 3.1 e 3.2, a seguir, descrevemos o processamento dos efeitos informativo e emotivo positivos na interpretação de enunciados.

\subsection{EFEITO INFORMATIVO}

Para que a explanação do esquema da figura 1 seja objetiva aos propósitos deste estudo, retomemos o caso do atleta paraolímpico Thiago Paulino. Embora não tenhamos acesso ao instante em que o atleta foi informado sobre a perda da medalha de ouro, podemos construir um contexto discursivo hipotético no qual teria ocorrido o seguinte enunciado proferido pelo representante do Comitê Paralímpico Brasileiro:

(1) Thiago, os chineses entraram com recurso, e os juízes deram causa a eles. Você é bronze.

O enunciado (1) pode ser caracterizado como um enunciado elicitativo, porque, além de informativo, gera processos mentais de elicitação, ou seja, gera reações emocionais (WHARTON et al, 2021). Embora a maioria das pesquisas sobre emoções foque a elicitação como um procedimento deliberado (intencional), o enunciado elicitativo (1) não tem essa pretensão deliberada, isto é, a intenção do falante é antes informar do que produzir emoções. Como o foco do nosso trabalho se centra nos processos de interpretação desse enunciado, ficam fora do seu escopo os processos de produção de enunciados elicitativos (embora o esquema da figura 1 possibilite a descrição desse procedimento mental).

Sob a ótica proposta na figura 1 , o processamento cognitivo de interpretação do enunciado (1) ocorreu da seguinte maneira. A sequência sonora do input linguístico, ao 
entrar na mente do atleta, chega à sua 'atenção seletiva', estrutura mental que tem a propriedade de selecionar inconscientemente as informações relevantes e ignorar as informações irrelevantes (KIHLSTROM, 1987). ${ }^{9}$

Mas, como a 'atenção seletiva' distingue o que é relevante do que é irrelevante? Nossa proposta é a de que ela é estimulada pela estrutura 'interesse'. O interesse é o estado mental que, psicocognitivamente, torna as informações que chegam às percepções sensoriais mais nítidas e intensas ao indivíduo. Nesse estágio, a ostensão do falante desempenha um papel preponderante.

Após ser selecionada pela 'atenção seletiva' a sequência sonora chega à estrutura 'integração sensorial', que codifica o input em uma linguagem mental, nomeada de forma lógica por Sperber e Wilson (2001) e Ledoux (1996). A cognição envia a forma lógica à 'memória de curta duração', estrutura que integra em tempo real as informações novas com as representações dos conceitos armazenados na 'memória enciclopédica' (IZQUIERDO, 2011). Como isso ocorre? Vimos nos parágrafos anteriores que o desejo se compõe de duas propriedades cognitivas: querer e gostar. O enunciado, sendo novo ao ouvinte, ainda não gerou um efeito aprazível/não aprazível, isto é, o ouvinte não pode "gostar" ou "não gostar" de algo que ainda não representou mentalmente. Mas, o ouvinte pode "querer" conhecer a informação do enunciado. Sendo assim, por tratar-se de informação nova, a cognição excita a estrutura 'desejo', a qual dispara na estrutura 'interesse' o gatilho "quero conhecer" o conteúdo do enunciado.

Essa hipótese nos leva a conferir que, embora a forma lógica do enunciado chegue às 'estruturas límbicas' concomitantemente à 'memória enciclopédica', o processamento emocional, salvaguardado o caso das emoções emergenciais, só tem lugar depois que a cognição atribuir um efeito à informação, isto é, após a cognição alocar o conteúdo informativo do enunciado em uma representação de mundo para o ouvinte ${ }^{10}$. Como veremos, só após esse procedimento é que tem lugar o "gostar" disparado pela estrutura 'desejo'.

Da 'memória de curta duração' a forma lógica é orientada para três estruturas simultaneamente: 'memória enciclopédica', 'estruturas límbicas' e 'beleléu'. Descreveremos primeiramente o procedimento que delineia a interpretação informativa e, na sequência, descreveremos o movimento das 'estruturas límbicas'.

$\mathrm{Na}$ 'memória enciclopédica', a forma lógica é submetida à verificação da possibilidade de já se encontrar nesta memória alguma referência informativa sobre o input. Se já houver ali uma representação conceitual do input, a cognição cessa o processamento, afinal, quem se interessaria por um conhecimento já disponível? Não havendo na 'memória enciclopédica' nenhuma representação conceitual correspondente à informação nova, a forma lógica é enviada à estrutura 'interesse' que, engatilhada pelo ‘desejo', dispara o 'interesse' pela informação. Para a psicologia, o 'interesse' é a

\footnotetext{
${ }^{9}$ Segundo Kihlstrom (1987), a mente efetua operações complexas cujo resultado pode se transformar em conteúdo consciente, embora não tenhamos acesso consciente a tais operações e conteúdos.

${ }^{10}$ Note-se que a forma lógica do enunciado chega primeiramente às estruturas límbicas e só depois de passar pela memória enciclopédica e pela estrutura interesse é que chega à memória operacional. Isso significa que, de acordo com Ledoux (1996), as emoções são engatilhadas, mas não acionadas, antes do processamento inferencial.
} 
propriedade cognitiva de busca da satisfação de uma necessidade momentânea (NASSIF, 2008). A forma lógica, despertando o 'interesse' do ouvinte, estimula a estrutura 'expectativa de relevância', estrutura responsável por tornar manifesta ao ouvinte, em maior ou menor grau, a informação contida na forma lógica. Se estivermos corretos, em conformidade com a teoria da relevância, este é o estágio do processamento mental no qual, presumivelmente, tem lugar a cláusula "a" da relevância (um enunciado é relevante o suficiente para merecer esforço de processamento do ouvinte), cláusula essa que é construída sobre as crenças intrínsecas do ouvinte (SPERBER, 1997) ${ }^{11}$.

Destarte, é bastante plausível a ideia de que, cognitivamente, a 'expectativa de relevância' seja uma propriedade imanente da estrutura 'interesse', isto é, a estrutura 'interesse' contenha a 'expectativa de relevância'. Em tal hipótese, como o 'desejo' é a propriedade que estimula o 'interesse', é de se presumir que caso o 'desejo' não desperte o 'interesse' em satisfazer uma necessidade momentânea ao ouvinte, a cognição não gerará 'expectativa de relevância' à forma lógica, o que acarretará a sua não manifestabilidade. A forma lógica não manifesta ao ouvinte não pode ser submetida ao processamento inferencial. Segue-se disso que a forma lógica não desejada, não interessante, não relevante e não manifesta ao ouvinte será descartada ao 'beleléu' via 'memória de curta duração'. Estas ponderações sugerem que o processamento interpretativo tem origem no 'desejo' e em função disso, como veremos adiante, é defensável a ideia de que o 'desejo' é o gatilho psicocognitivo que dispara a 'relevância' do processamento de interpretação humano.

A forma lógica de interesse do ouvinte é, por sua vez, submetida ao crivo da 'memória operacional', estrutura que processa todas as informações contextuais oriundas dos estímulos sensoriais ativados no instante da enunciação e as representações conceituais já armazenadas na 'memória enciclopédica', de modo que o produto dessas operações inferenciais é um misto da informação nova com as representações enciclopédicas. Dizemos que esse produto é a 'imagem mental' do enunciado (BASTOS, 1991). Metaforicamente, chamamos essa imagem mental de holograma semântico $H$.

De acordo com Penz (2019), o holograma semântico é a imagem virtual, a figura, a representação que a cognição cria para o conteúdo do enunciado ${ }^{12}$. Em outras palavras: o holograma semântico é a projeção da "forma do conteúdo" do enunciado no mundo mental do ouvinte (ou em um mundo provável/possível a ele), e a representação imagética desse holograma corresponde ao que tradicionalmente se conhece por proposição. ${ }^{13}$ No entanto, essa imagem proposicional somente se constituirá como tal se, neste ponto do processamento, o holograma "encaixar-se" no mundo do ouvinte (ou em um mundo provável/possível para ele), isto é, se ela "fizer/tiver sentido" para o ouvinte. Se assim for, a cognição envia o holograma à 'vigilância epistêmica'.

Para Sperber et al. (2010), a 'vigilância epistêmica' é um raciocínio avaliativo que a cognição faz sobre o quão confiável é a pessoa com a qual interagimos. Dizemos, então,

\footnotetext{
${ }^{11}$ Para Sperber (1997) a crença intrínseca é um propósito de acreditação baseado na percepção sensorial.

12 Para Sternberg (2010) a imagem mental pode envolver representações de qualquer das modalidades sensoriais, como audição, olfato ou paladar.

${ }^{13}$ Este conceito será crucial para a descrição da natureza do efeito informativo e emotivo. Note-se que este é do domínio semântico da interpretação.
} 
que a 'vigilância epistêmica' é a guardiã da verdade do enunciado, isto é, ela verifica, de acordo com as crenças intuitivas e reflexivas, se o holograma $\mathrm{H}$ tem/faz sentido no (ou em um) mundo do ouvinte. Caso o holograma não tenha sentido, não corresponda à verdade e não seja do interesse do ouvinte, a cognição suspende a atividade da 'memória operacional', e o processamento interpretativo cessa.

Por outro lado, caso o holograma corresponda a uma imagem mesmo que vaga e nebulosa, mas seja do interesse do ouvinte, a 'vigilância epistêmica' lhe atribui uma verdade fraca, o que vai implicar uma relevância igualmente fraca. Nesses casos, a 'vigilância epistêmica' reenvia a imagem vaga à 'memória operacional' para que a imagem seja novamente submetida a inferências e, nesse processo, seja fortalecida pelas representações conceituais já estabelecidas na 'memória enciclopédica' e adquira um formato mental que atenda às expectativas de relevância informativa. Trata-se de um procedimento importante, porque incide sobre os custos operacionais do processamento.

A imagem fortalecida inferencialmente e filtrada pela 'vigilância epistêmica' é enviada à estrutura 'relevância'. Para Sperber e Wilson (2001), a relevância é uma propriedade cognitiva mediada pelo esforço da 'memória operacional' na geração da imagem/holograma e a tomada de consciência do efeito dessa imagem. Os autores explicam que, embora o esforço expresse um processamento não representacional, a relevância pode ser uma propriedade de juízo representacional, isto é,

[...] a relevância é uma propriedade que não necessita estar representada, quanto mais computada, para ser conseguida. Quando está representada, está representada em termos de juízos comparativos de juízos mais ou menos absolutos (p. ex. "não relevante", "fracamente relevante", "muito relevante") [...]. (SPERBER; WILSON, 2001, p. 207).

Como o enunciado (1) é uma novidade ao atleta, ocorre na estrutura 'relevância' a saturação do desejo "querer", isto é, o desejo pelo conhecimento da informação atinge o juízo "muito relevante". Esta presunção nos leva a apostarmos na ideia de que este é o estágio mental no qual, para a teoria da relevância, ocorre a "otimização" da relevância informativa, isto é, são cognitivamente satisfeitas as 'expectativas de relevância' disparadas no início do processo. Se assim for, podemos afirmar que o desejo intelectual é um querer humano que orienta a cognição à otimização da relevância informativa. Como o desejo intelectual comanda a estrutura 'interesse', e essa estrutura mantém estreita relação com a estrutura 'relevância', quanto mais o ouvinte deseja acessar a informação, mais relevante ela se torna e vice-versa. Essa dinâmica cognitiva nos afiança a afirmar que o 'desejo' é o gatilho da 'relevância' da interpretação humana.

Segue-se disso que o holograma potencializado à relevância ótima é enviado à estrutura 'efeito', onde será enriquecido pelas crenças reflexivas do ouvinte (SPERBER, 1997) ${ }^{14}$, tais como conhecimentos, experiências, vivências, ambições, intenções e atitudes, elementos contextuais que incidem sobre o significado para o ouvinte. A esse efeito Sperber e Wilson (2001) chamam de efeito positivo. Wharton et al. (2021), no entanto, ressaltam que os efeitos cognitivos positivos descritos pelos autores são, na realidade, efeitos epistêmicos positivos, ou seja, efeitos que são positivos em relação ao objetivo de melhorar o conhecimento do indivíduo em quantidade e/ou em qualidade.

${ }^{14}$ Para Sperber (1997) a crença reflexiva é uma atitude proposicional reflexiva derivada de uma inferência sobre uma representação conceitual. 
Nesse processo, inferimos que a relevância ótima só é atingida quando o ouvinte atribui um efeito epistêmico "na medida certa" ao enunciado. Esta presunção, no entanto, tem um precedente cognitivo: a quantidade "certa" de efeito que o ouvinte atribui à interpretação é determinada por sua capacidade cognitivo-inferencial e por suas representações conceituais intrínsecas. Cognitivamente, o efeito epistêmico diz respeito à atividade mental que valida a verdade (provável ou possível) da imagem do enunciado em um estado de mundo para o ouvinte. Isto significa que a relevância ótima e o efeito epistêmico são as duas propriedades cognitivas basilares da interpretação informativa.

Para melhor esclarecer essa ideia, ilustramos no gráfico 1 o movimento cognitivo do efeito epistêmico resultante da otimização da relevância informativa na interpretação do enunciado (1).

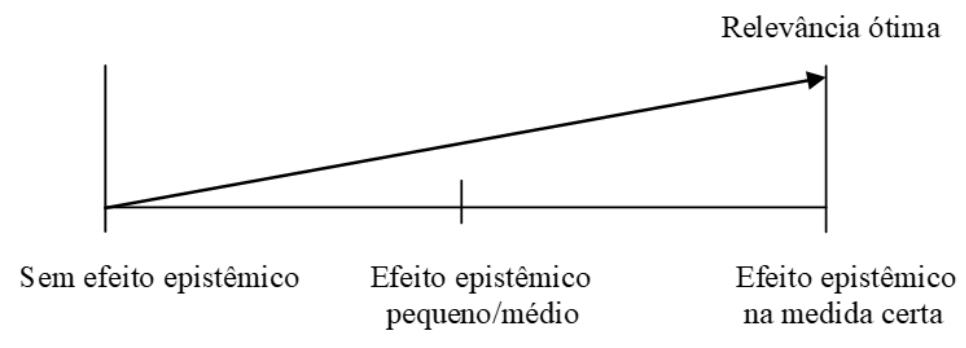

\section{Gráfico 1 - Modalização do efeito epistêmico}

Fonte: Adaptado de Santos e Godoy (2020, p. 52)

Uma vez saturado o efeito epistêmico (atingida a relevância ótima) no nível da consciência, o holograma $\mathrm{H}$ tem uma implicação contextual para o ouvinte - uma experiência mental. A tomada de consciência da imagem-holograma é o que nós chamamos 'significado' (representado por H1 na figura 1). Destacamos que este estágio é do domínio da pragmática, posto que a evolução de $\mathrm{H}$ para $\mathrm{H} 1$ corresponde ao enriquecimento contextual atribuído pelo efeito ao holograma. Aqui, deve ficar claro que, de acordo com Kihlstrom (1987), o ‘significado' para o ouvinte corresponde ao estado consciente do conteúdo proposicional do enunciado, enquanto o ouvinte não tem consciência das operações cognitivas do processamento interpretativo em si.

Perfazendo o percurso interpretativo, o holograma $\mathrm{H} 1$ de "Os chineses entraram com recurso e os juízes deram causa a eles. Você é bronze" segue à "memória enciclopédica', onde se fixa no formato de nova representação conceitual, isto é, o ouvinte adquire um conhecimento novo. Uma vez atingido esse estágio, a estrutura 'interesse' age sobre a 'memória operacional' para que cesse o processamento inferencial. Cognitivamente, é como se a mente do ouvinte reagisse à informação nova e dissesse: "Entendi o enunciado e acredito na verdade da informação". A aceitação ou não da informação pelo ouvinte é um processo que descreveremos no próximo tópico.

Chamamos a atenção, no entanto, para o fato de que se a 'vigilância epistêmica' não detectar a falsidade de uma informação, a cognição irá validar o efeito como verdadeiro e o significado será armazenado na 'memória enciclopédica' como conhecimento novo. Assim se configura a mentira. Contudo, a mentira só se constitui 
como tal quando a imagem-holograma $\mathrm{H}$ corresponde à (falsa) verdade para alguém. A verdade-mentira só será refutada quando uma nova informação imponha um significado que contradiga a representação mentirosa armazenada na 'memória enciclopédica'. Se isso não ocorrer, a verdade mentirosa guiará a vida social, epistêmica e afetiva do indivíduo.

\title{
3.2 EFEITO EMOTIVO
}

Não é surpresa para os cognitivistas afetivos, e nem mesmo para os racionalistas da razão nobre, embora eles a ignorem, que o enunciado "Os chineses entraram com recurso e os juízes deram causa a eles. Você é bronze" tenha provocado em Thiago, além do efeito informativo, como acabamos de descrever, algum efeito emotivo. Afinal, a relevância da informação é tão contundente que é impossível o atleta ficar afetivamente apático à notícia.

Para Damásio (1994, p. 277):

\begin{abstract}
Conhecer a relevância das emoções nos processos de raciocínio não significa que a razão seja menos importante do que as emoções, que deva ser relegada para segundo plano ou deva ser menos cultivada. Pelo contrário, ao verificarmos a função alargada das emoções, é possível realçar seus efeitos positivos e reduzir seu potencial negativo. Em particular, sem diminuir o valor da orientação das emoções normais, é natural que se queira proteger a razão da fraqueza que as emoções anormais ou a manipulação podem provocar no processo de planeamento e decisão.
\end{abstract}

As palavras de Damásio são compatíveis com nosso recente estudo no qual propusemos que intercâmbios conversacionais geram reações de bem-estar e/ou de malestar, níveis psicocognitivos que formatam a interpretação afetiva humana (SANTOS; GODOY, 2020). Nesse estudo, explicitamos que o bem-estar gera a emoção básica alegria, que conduz o efeito afetivo aos estados contentamento, satisfação, amor e felicidade, estados esses que formam os sentimentos positivos humanos. Já o mal-estar se manifesta em quatro emoções básicas: tristeza, raiva, medo e nojo. A tristeza provoca os sentimentos negativos decepção, insatisfação, vergonha e frustração; a raiva conduz aos sentimentos irritação, fúria, aborrecimento e ódio; o medo dispara a ameaça, ansiedade, intimidação, ciúme e inveja; e o nojo gera repugnância, asco e náusea.

No caso em discussão, é defensável a ideia de que a interpretação do atleta não dispara a pré-emoção bem-estar, o que extingue a possibilidade de a emoção alegria ter sido ativada, bem como os sentimentos categorizados pelo contentamento, satisfação, amor e felicidade. Parece também não ser o caso de a interpretação ativar as emoções básicas medo e nojo, o que descarta a possibilidade de serem ativados os sentimentos categorizados por essas emoções. Não podemos ignorar, porém, a ideia de que o enunciado (1) tenha disparado as emoções básicas tristeza e raiva em Thiago. ${ }^{15}$ Segundo

\footnotetext{
${ }^{15}$ Pesquisas recentes apontam que não há um cérebro emocional separado do resto do cérebro, mas uma
} rede complexa de sistemas neurais subjacentes a comportamentos emocionais específicos. Destarte, o 
Russell (1991), este despertar emotivo é categorizado nos sentimentos decepção/insatisfação pelas emoções cognitivas primárias e em aborrecimento/ódio pelas emoções cognitivas secundárias.

Acompanhemos na figura 1 a descrição da influência da emoção tristeza na interpretação do atleta.

Vimos nas páginas anteriores que a forma lógica oriunda da 'memória de curta duração' é concomitante à 'memória enciclopédica' e às 'estruturas límbicas'. De acordo com Ledoux (1996), a forma lógica percorre dois trajetos distintos quando chega às estruturas límbicas: um principal, via córtex sensorial e deste à amígdala, e outro secundário, de onde segue do tálamo sensorial diretamente à amígdala ${ }^{16}$.

As 'estruturas límbicas' ativam a estrutura 'desejo', estrutura mental que vai disparar a contraparte emocional "gostar/não gostar" do desejo epistêmico 'querer' para a forma lógica. Psicologicamente, o desejo emocional é um impulso que impele o ser humano à busca pela satisfação e pelo prazer e inibe a insatisfação e o desprazer. Cognitivamente, o desejo emocional é uma atividade que comanda a valoração afetiva da interpretação humana, valoração essa que vai culminar na maximização positiva ou negativa da relevância do enunciado. É o que nós chamamos de relevância emotiva (RE) em Santos e Godoy (2020).

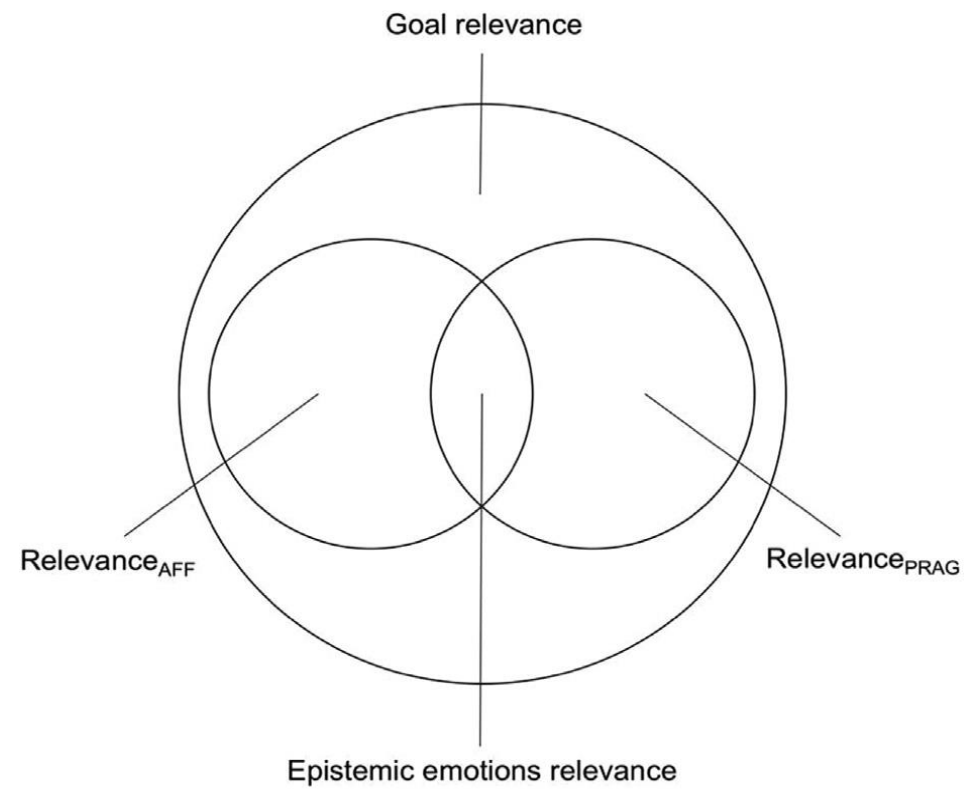

\section{Figura 2 - Relevância afetiva e relevância pragmática}

Fonte: Wharton et al. (2021, p. 266).

efeito emotivo na interpretação de enunciados não corresponde à ativação de uma única estrutural mental, mas é resultado do processamento dessa rede complexa de estruturas.

${ }^{16}$ Destacamos que este último trajeto é ativado somente em condições emocionais emergenciais, tais como perigo/ameaça. Goleman (1996) nomeou a ativação das estruturas emocionais emergenciais de 'o sequestro da amígdala' ou 'sequestro emocional'. 
Wharton et al. (2021) pressupõem que a relevância emotiva e a relevância informativa são subtipos de um tipo mais geral de relevância ${ }^{17}$ : a relevância do objetivo/meta ${ }^{18}$. Segundo Wharton et al (2021, p. 265), quando se trata de metas, a relevância afetiva "se refere a qualquer tipo de objetivo que pode levar a uma reação emocional (com emoções diferentes tipicamente ligadas a objetivos diferentes) de objetivo básico"19. Os autores esquematizam as duas relevâncias conforme a figura 2.

A intersecção das duas relevâncias forma a zona de convergência, à qual os autores nomeiam de relevância das emoções epistêmicas. As emoções epistêmicas constituem fenômenos ou reações emocionais que presumivelmente instanciam relevância afetiva, bem como se referem ao objetivo de adquirir conhecimento. Segundo os autores, a relevância afetiva maximiza os efeitos cognitivos relevantes e minimiza os esforços de processamento em certos episódios afetivos, como sentimentos afetivos. Isso sugere que a consolidação do efeito epistêmico não precisa constituir uma limitação rígida de exclusão de qualquer outro tipo de efeito na investigação pragmática.

De acordo com Wharton et al. (2021, p. 266):

\begin{abstract}
É verdade que a teoria da relevância tem se concentrado em processos que envolvem a compreensão de conteúdos proposicionais comunicados ostensivamente, mas isso pode ser considerado uma contingência histórica, uma consequência do fato de a teoria da relevância ter se originado da pesquisa linguística. Se considerarmos mais uma vez uma emoção epistêmica como o interesse, vemos que as duas noções de relevância parecem se aplicar. ${ }^{20}$
\end{abstract}

Destarte, no caso do enunciado (1), a relevância emotiva, em conjunto com a relevância informativa, dispara o efeito emotivo para o atleta, efeito que será maximizado negativamente, de acordo com a valência e o potencial psicológico correlatos à categoria "tristeza" da "memória emotiva'. ${ }^{21}$ Segundo Saussure e Wharton (2020), o atleta experimenta uma sensação de "desprazer" nesse estágio. O conteúdo dessa excitação será armazenado na 'memória emotiva' como a experiência/vivência do efeito emotivo do enunciado (GAZZANIGA; IVRY; MAGNUM, 2006). ${ }^{22}$ Psicocognitivamente, é como se a mente do atleta dissesse: "Estou insatisfeita com o conteúdo do enunciado".

17 Wharton et al (2021) chama a relevância informativa de relevância pragmática e a relevância emotiva, de relevância afetiva.

${ }^{18}$ De acordo com Rauen (2014), objetivo e meta são propriedades imanentes da cognição para a resolução de um conflito/problema.

${ }^{19}$ No original: "relates to any kind of goal that may lead to an emotional reaction (with different emotions typically linked to different goals) e from basic goals".

${ }^{20}$ No original: "It is true that relevance theory has focused on processes that involve the comprehension of ostensively communicated propositional contents, but this may be considered a historical contingency, a consequence of the fact that relevance theory originated from research in linguistics. If we consider once again an epistemic emotion such as interest, we see that the two notions of relevance seem to apply."

${ }^{21}$ De acordo com Esperidião-Antonio et al (2008), o que determina a categorização das emoções é o tipo de excitação neuroquímica demandada pelas estruturas límbicas, grosso modo, serotonina para a felicidade, adrenalina para o medo, dopamina para o prazer e o nojo, endorfina para a euforia, ácido gama-aminobutírico para a calma, ocitocina para a empatia e cortisol para a raiva.

${ }^{22}$ Bastos (1991) cogita a hipótese de uma imagem emocional. Segundo o autor, a imagem emocional pode ser tratada como uma manifestação cerebral estruturada na forma de conceitos, capaz de controlar padrões somato-viscerais específicos. 
Segue-se daí que, de acordo com Newman e Zink (2013), o efeito emocional maximizado potencializa as reações neuroquímicas nas 'estruturas límbicas', aumentando o grau de saturação dessas reações e, em consequência, o tempo de dissipação químiconeuronal. Por isso afirmamos que o efeito emotivo é flutuante e, sendo assim, perdura até a dissipação total das reações neuroquímicas. De acordo com Esperidião-Antonio et al (2008), a tendência natural é que a dissipação ocorra em poucos segundos nas emoções básicas; para os sentimentos, contudo, a dissipação pode perdurar de minutos a dias, meses ou anos.

Ilustramos no gráfico 2 como se configura a relação relevância emotiva (RE) para o efeito emotivo do enunciado "Os chineses entraram com recurso e os juízes deram causa a eles. Você é bronze".

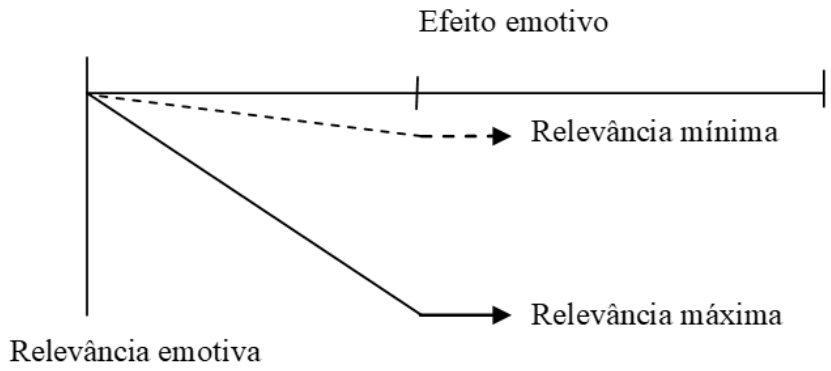

\section{Gráfico 2 - Maximização da relevância emotiva para o efeito emotivo negativo}

Fonte: Os autores.

De acordo com Victória e Soares (2017), quando há concordância entre o conteúdo emocional da informação a ser tratada e o estado emocional do ouvinte, há o fortalecimento da representação emocional e informativa nas respectivas memórias, de modo a melhorar e agilizar o acesso às representações quando estas venham a ser requeridas em um novo processamento. Como há uma correlação representacional entre a 'memória enciclopédica' e a 'memória emotiva' (ver figura 1), cada vez que um input sensorial sobre o fato ativar a 'memória enciclopédica' do atleta, seja por intermédio de um estímulo externo, seja por estímulos internos (evocações, lembranças, vontades, necessidades etc.), haverá a excitação do sentimento "tristeza" em sua 'memória emotiva'.

Além da tristeza, em um segundo momento, a cognição do atleta pode também disparar a emoção raiva, que, permeada pelas representações conceituais da 'memória enciclopédica' e amplificada pelas crenças, valores e experiências, será moldada como sentimento irritação ${ }^{23}$. Hülsoff $(2000$, p. 13) destaca que "a irritação é uma reação hostil a determinado estímulo. Ainda que o primeiro impulso dure apenas alguns segundos, o estado pode perdurar mais tempo e ser reavivado a qualquer momento". Por raiva, o autor define uma emoção mais densa e explosiva na qual a irritação dispara uma reação imediata de dissipação de uma energia represada. "Quando raiva e irritação se voltam

${ }^{23}$ Para Saussure e Wharton (2020) o sentimento é o estado mental de sentir a emoção (sentir medo, sentir raiva, sentir nojo, alegria, tristeza). 
para um determinado alvo por um período de tempo maior, falamos em ódio", complementa (2000, p. 13). A raiva pode, em casos extremos, evoluir para estados emocionais que culminam em acessos de fúria (MALINVERINI, 2000). Embora não seja o caso, de acordo com Hülsoff (2000), a irritação também pode transformar-se em desejo de vingança, quando é provocada por uma ofensa.

\section{CONSIDERAÇÕES FINAIS}

Defendemos neste artigo a hipótese de que o 'desejo' é o gatilho do processo inferencial e, em consequência, influencia quantitativa e qualitativamente a interpretação humana. Essa hipótese se apoia na ideia de que a interpretação afetiva auxilia a cognição a restringir ou aumentar a construção do contexto, fortalecendo-o ou enfraquecendo-o com material emocional, de modo a tornar os fundamentos informativos, proposicionais, da 'memória enciclopédica' mais salientes, mais acessíveis e mais sensíveis a novos inputs.

Segue disso que, de acordo com Zuo (2018), quando a informação vem acompanhada de emoção, sua representação conceitual é mais forte. O aceite dessa hipótese refuta a ideia da contaminação da relevância informativa pela relevância afetiva, posto que, como vimos, no caso do processamento de interpretação de uma informação nova, o desejo pelo conhecimento informativo sempre vai prevalecer inicialmente sobre o emotivo ${ }^{24}$. Isso sugere que razão e emoções, tantas vezes tomadas como antagônicas, trabalham cognitivamente juntas nas estratégias interpretativas.

Nesse sentido, as emoções funcionam como agentes pragmáticos para o efeito cognitivo, posto que elas impulsionam a cognição na busca por relevância, facilitando a identificação e a seleção do que vale a pena ser processado (WILUTZKY, 2015). Em outras palavras, as emoções e sentimentos funcionam como parte essencial da busca por relevância informativa, isto é, auxiliam a cognição no processo de decisão e raciocínio, filtrando drasticamente as hipóteses e os cenários futuros e tornando (mais) manifesto aquilo que é (mais) relevante à interpretação. De acordo com Greenspan (2002), as emoções funcionam como causas habilitadoras da tomada de decisão racional na medida em que direcionam a 'atenção seletiva' para certos objetos do pensamento e distanciamna de outros. As emoções servem para limitar o conjunto de opções práticas salientes para um conjunto gerenciável, adequado para uma rápida tomada de decisão. A emoção medo, por exemplo, equipa a 'atenção seletiva' com um conjunto totalmente novo de metas e prioriza os processos inferenciais radicais, tornando o indivíduo muito mais alerta.

Destarte, destacamos que um dos méritos deste estudo é harmonizar-se com os fundamentos da teoria da relevância, uma vez que ficam preservados os conceitos de "relevância" e de "efeito" oriundos do processamento inferencial. Isto é, declina-se a ideia de que o efeito emotivo se interpõe incondicionalmente em todas as situações de interpretação, trivializando o efeito informativo. Dessa forma, esta abordagem mostra-se promissora para os estudos pragmáticos, visto que a relação "informatividade versus

${ }^{24}$ Com salvaguardas às emoções emergenciais. 
emotividade" é ainda um caminho a trilhar. Estudos adicionais precisarão articular com mais detalhes como a afetividade responde aos princípios gerais de produção e de interpretação de enunciados elicitativos. Afinal, sentimentos e emoções podem funcionar como atratores da atenção ou podem acelerar o processo cognitivo aperfeiçoando a noção de que a mente humana é orientada para a relevância.

\section{REFERÊNCIAS}

ARAÚJO, T. P. de. O desejo na psicanálise: do objeto do desejo ao objeto causa de desejo. $120 \mathrm{f}$. Dissertação (Mestrado em Psicologia). Programa de Pós-graduação em Psicologia. Universidade Federal de Goiás. Goiânia, 2018.

BARD, P. A Diencephalic Mechanism for the Expression of Rage with Special Reference to the Sympathetic Nervous System. American Journal of Physiology-Legacy Content, v. 84, n. 3, p. 490-515, 1928.

BASTOS, M. C. Emoção e cognição: questões a partir de duas perspectivas. 1996. $101 \mathrm{f}$. Dissertação (Mestrado em Psicologia) - Programa de Pós-graduação em Psicologia, Fundação Getúlio Vargas, Rio de Janeiro, 1996.

BLAKEMORE, D. On the Descriptive Ineffability of Expressive Meaning. Journal of Pragmatics, v. 43, p. 3537-3550, 2011.

CANNON, Walter B. The James-Lange theory of emotions: A critical examination and an alternative theory. The American journal of psychology, v. 39, n. 1/4, p. 106-124, 1927.

CARTER, R. et al. O livro do cérebro. Tradução de Francis Jones. Rio de Janeiro: Agir, 2012.

CHAUÍ, M. Desejo, paixão e ação na ética de Espinosa. São Paulo: Companhia das Letras, 2011.

COSMIDES, L.; TOOBY, J. The Evolutionary Psychology of the Emotions and their Relationship to Internal Regulatory Variables. In LEWIS, M.; HAVILAND-JONES, J. M.; BARRETT, L. F. (Eds.). Handbook of Emotions. 3rd. ed. Nova York: Guilford. 2008. p. 114-137.

COSTA, J. C. da. A Teoria da relevância e as irrelevâncias da vida cotidiana. Linguagem em (Dis)curso, v. 5, número especial, p. 161-169, set-dez. 2005.

DAMÁSIO, A. R. O erro de Descartes: emoção, razão e o cérebro humano. 11. ed. São Paulo: Companhia da Letras, 1994.

DAMÁSIO, A. R. Em busca de Espinosa: prazer e dor na ciência dos sentimentos. São Paulo: Companhia da Letras, 2004.

DI BIASE, F; AMOSOROSO, R. A revolução da consciência: novas descobertas sobre a mente no século XXI. Petrópolis: Vozes, 2005.

ESPINOSA, B. de. Tratado da correção do intelecto. São Paulo: Nova Cultural, 1997. (Coleção: Os pensadores).

ESPERIDIÃO-ANTONIO, V.; MAJESKI-COLOMBO, M.; TOLEDO-MONTEVERDE, D., MORAESMARTINS, G.; FERNANDES, J. J.; ASSIS, M. B. de; SIQUEIRA-BATISTA, R. Neurobiologia das emoções. Revista Psiquiatria Clínica. v. 35, n. 2, p. 55-65, 2008.

GAZZANIGA, M. S.; IVRY, R. B.; MAGNUN, G. R. Neurociência Cognitiva: a biologia da mente. Tradução de vários autores. 2. ed. São Paulo: Artmed-Bookman, 2006.

GOLEMAN, D. Inteligência emocional. Trad. M. Santarrita. Rio de Janeiro, Objetiva. 1996.

GREENSPAN, P. Practical Reasoning and Emotion. In MELE, A.; RAWLINGS, P. (Eds.). Rationality. New York: Oxford University Press, 2002. p. 206-221

HILL, C. S. Consciência. São Paulo: Unesp. 2011.

HÜLSOFF, T. Loucos de raiva. In: LEAL, Gláucia (Org.). O equilíbrio das emoções. Revista Mente e Cérebro, edição especial. São Paulo: Duetto, 2000, v. 9, p. 12-15.

IZQUIERDO, I. Memória. Porto Alegre: Artmed, 2011.

JAMES, W. What is an emotion? Mind, Oxford Journals, v. 9. n. 34, p. 188-205, abr., 1884. Disponível em: http://gruberpeplab.com/3131/James_1884_WhatisanEmotion.pdf. Acesso em 11.02. 2020. 
KIHLSTROM, J. F. The cognitive unconscious. Science, v. 237, p. 1445-1452, 1987. Disponível em: https://www.ocf.berkeley.edu/ jfkihlstrom/PDFs/1980s/1987/ScienceCogUncog.pdf. Acesso em 27.08.2020.

LANGE, Carl G. The Emotions. In: DUNLAP, K. (ed.). The Emotions. Baltimore: Waverly Press, 1922. p. 33-90

LEDOUX, J. O cérebro emocional: os misteriosos alicerces da vida emocional. Rio de Janeiro: Objetiva, 1996.

MALINVERINI, G. Raízes da violência. In: LEAL, Gláucia (Org.). O equilíbrio das emoções. Revista Mente e cérebro edição especial. São Paulo: Duetto, v. 9, p. 18-23, 2000.

MERCIER, H; SPERBER, D. The Enigma of Reason: A New Theory of Human Understanding. Cambridge, Massachusetts: Harvard University, 2017.

MOESCHLER, J. Pragmatics, Propositional and Non-Propositional Effects: Can A Theory of Utterance Interpretation Account for Emotions in Verbal Communication? Social Science Information, Special Issue: The Language of Emotion - Conceptual and Cultural Issues, v. 48, n. 3, p. 447-464, 2009.

NASSIF, L. E. O conceito de interesse na Psicologia Funcional de Edouard Claparède: da chave biológica à interpretação interacionista da vida mental. 169 f. Tese (Doutorado em Educação). Programa de Pós-graduação em Educação. Universidade Federal de Minas Gerais. Belo Horizonte, 2008.

NEWMAN. A.; ZINK, A. O jogo das emoções. In: LEAL, G. O desafio das emoções. Revista Biblioteca Mente e Cérebro, v. 5. São Paulo: Duetto, p. 11-21, 2013.

PAPEZ, J. W. A Proposed Mechanism of Emotion. Archives of Neurology \& Psychiatry, v. 38, n. 4, p. 725-743, 1937,

PENZ, Y. F. da S. Hologramas semânticos: uma proposta metateórica para a avaliação do significado complexo na linguagem natural. Letrônica, Porto Alegre, v. 12, n. 2, abr./jun. 2019.

RAUEN, F. J. Sobre relevância e irrelevâncias. In: COSTA, J. C. da; RAUEN, F. J. (Org.). Tópicos em Teoria da Relevância. Porto Alegre: Edipucrs, v. 1, p. 26-56, 2008.

RAUEN, F. J. For a goal conciliation theory: ante-factual abductive hypotheses and proactive modelling. Linguagem em (Dis)curso, Tubarão, SC, v. 14, n. 3, p. 595-615, 2014.

RUSSELL, J. A. Culture and Categorization of Emotions. Psychological Bulletin, v. 110, n. 3, p. 426450. 1991. Disponível em: https://www.semanticscholar.org/paper/Culture-and-the-categorization-ofemotions.-Russell/774e783c2f8921c6030359f05683b17fcda16d57. Acesso em: 5 dez. 2019.

SANTOS, S. L; GODOY, E. Efeito racional e efeito emocional: um estudo pragmático da cognição humana. Revista Memorare, Dossiê Especial Pragmática: desenvolvimentos e extensões, Tubarão, v. 7, n. 2, maio/ago., p. 44-58, 2020.

SAUSSURE, L. de; WHARTON, T. Relevance, Effects and Affect. International Review of Pragmatics, n. 12, p. 183-205, 2020.

SCHACHTER, S.; SINGER, J. Cognitive, Social, and Physiological Determinants of Emotional State. Psychological Review, v. 69, n. 5, 379, 1962.

SCARANTINO, A. How to Do Things With Emotional Expressions: The Theory of Affective Pragmatics. Psychological Inquiry, v. 28, n. 2-3, p. 165-185, 2017.

SCHNALL, S. The Pragmatics of Emotion Language. Psychological Inquiry, v. 16, n. 1, p. 28-31, 2005.

SEARLE, J. S. Os actos de fala: um ensaio de filosofia da linguagem. Tradução de Carlos Vogt e outros. Coimbra: Almedina, 1969[1981].

SILVA, E. C. da. Conatus: da essência humana à fundamentação do estado na ética de benedictus de Spinoza. 2011. 131 f. Dissertação (Mestrado Acadêmico em Filosofia) - Programa de Pós-graduação em Filosofia, Universidade Estadual do Ceará, Fortaleza: 2011.

SPERBER, D.; WILSON, D. Relevância: comunicação e cognição. Lisboa: Fundação Calouste Gulbenkian, 2001.

SPERBER, D.; CLÉMENT, F.; HEINTZ, C.; MASCARO, O.; MERCIER, H.; ORIGGI, G. e WILSON, D. Epistemic vigilance. Mind \& Language, v. 25, n. 4, p. 359-393, 2010.

SPERBER, D. Intuitive and Reflective Beliefs. Mind and Language, v. 12, n. 1, p. 67-83, 1997.

SPERBER. D; WILSON, D. Beyond Speaker's Meaning. Croatian Journal of Philosophy, v. XV, p. $117-$ 149. 2015.

STERnBERG, R. J. Psicologia Cognitiva. Porto Alegre: ArtMed, 2010. 
VICTÓRIA, M. S.; SOARES, A. B. Estados emocionais e processamento cognitivo: sistemas dependentes? Revista Psicologia em Pesquisa. Juiz de Fora: UFJF. v. 1, n. 1, p. 15-19, jan./jun. 2007. WHARTON, T.; STREY, C. Slave to the Passions: Making Emotions Relevant. In: CARSTON, R.; CLARK, B.; SCOTT, K. (Eds.) Relevance Pragmatics and Interpretation. Cambridge: Cambridge University Press, 2019. p. 253-266.

WHARTON, T.; BONARD, C.; DUKES, D.; SANDERS, D.; STEVE, O. Relevance and emotion. Journal of Pragmatics, v. 181, p. 259-269, 2021.

WILSON, D.; CARSTON, R. Pragmatics and the Challenge of 'Non-propositional' Effects. Journal of Pragmatics, v. 145, p. 31-38, 2019.

WILUTZKY, W. Emotions as pragmatic and epistemic actions. Frontiers in Psychology, v. 6. 2015. Disponível em: https://www.frontiersin.org/articles/10.3389/fpsyg.2015.01593/full. Acesso em: 4 maio 2021.

ZUO, B. Emotive Misunderstanding within an Extended Relevance Theory. Intercultural Pragmatics, v. 15, p. 627-650, nov. 2018.

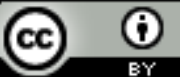

Este texto está licenciado com uma Licença Creative Commons Atribuição 4.0 Internacional. 